\title{
Wake Forest University: Building a campus-wide mentoring culture
}

\author{
Allison E. McWilliams
}

\begin{abstract}
This article describes recent efforts by Wake Forest University to develop a campus-wide mentoring culture to support holistic student development, to assist with the critical transition from high school to college to life after college, and to develop skills and practices that will be valued by employers and graduate schools. The article describes how the University's Mentoring Resource Center has been developed and uses a decentralized model of mentoring to support mentor and mentee skill development with online and in-person tools and strategies. The article in particular describes several key peer mentoring programs as examples of diverse program goals and participants that are supporting student transition and development. Finally, the article looks at measures of success and lessons learned that can be applied in the future.
\end{abstract}

\section{Keywords}

Peer, transition, college student, network

\section{Introduction}

Higher education has always fulfilled a student development role as part of its educational mission. Institutions have recognized over time the evolving needs of students transitioning from high school to college. Similarly, campus models of developmental support have evolved to meet those student needs, particularly through incorporating peer mentoring programs. Schools of all sizes and institution types have added peer mentors to existing support roles such as faculty advisors, residence life supervisors, and campus life coordinators. Peer mentors are trained to advise and guide their younger counterparts in everything from course selection to navigating first-year transition to career choices. Many of these peer-to-peer relationships are established through first-year experience programs aimed at diverse goals. These goals include: improving student success and persistence; easing the transition from high school to college; developing academic and social skills; building effective interpersonal relationships; exploring one's identity, beliefs, and values; and as a result, increasing retention rates (Sanft, Jensen, \& McMurray, 2008). At Wake Forest University, peer mentors play an important role in our efforts to support holistic student development, to assist with the critical transition from high school to college to life after college, to develop skills and practices that will be valued by employers and graduate schools, and ultimately to develop a campus-wide mentoring culture.

Not only do peer mentoring programs support first year students, they also provide a developmental opportunity for the older students who serve as mentors and who gain critical skills for creating and maintaining interpersonal relationships. Key to effectively fulfilling the role of peer mentor is a sound understanding of principles and theories of student development, and how those are enacted in practice. As Daloz Parks (2000) notes, traditional college-age students (those aged, roughly speaking, 
18-25) occupy an interesting place as “post-adolescent-not-yet-full-adult.” These not-yet-full-adults are beginning to explore critical questions of purpose, vocation, and belonging (p. 65). More recently, Arnett (2004) has labeled these "post-adolescent-not-yet-full-adults" as emerging adults. Neither fully adolescent nor fully adult, it is a period notable for its exploration but also for its instability, in both work and relationships, and a time to develop "an ideology, a world view, a way of making sense of the world" (p. 144; 165). Emerging adults, in each of these three areas (work, relationships, identityformation), are trying out possibilities and feel that they have "an unparalleled opportunity to transform their lives” (p. 8). But in doing so, they do not yet feel fully responsible for those lives, a criteria that they associate with the self-sufficiency and independence of adulthood.

The transitions from high school to college, and then to life after college, are therefore also transitions from adolescence to adulthood. These are key formative times in individuals' lives, when they discover personal beliefs, interests, values, strengths, and goals. It is a time of change and exploration that is for many a period of great excitement and opportunity. But it also can present challenges that seem overwhelming and that can lead to debilitating or destructive behavior and poor decisionmaking. As Arnett (2000) notes, this period of transition is "a time in life when many different directions remain possible, when little about the future has been decided for certain, when the scope of independent exploration of life's possibilities is greater for most people than it will be at any other period of the life course” (p. 469).

In addition to the work of emerging adulthood and its associated challenges and opportunities, researchers have identified several key factors that impact student development in college. These include: quantity and quality of involvement and engagement in campus life; the values, beliefs, experiences, and perceptions that students bring with them to college; engagement with the physical environment and individuals on campus; a sense of compatibility with the institution; and perhaps most importantly, the influence of one's social circle, which establishes norms for behavior and provides validation through inclusion, recognition, and acceptance (Newton \& Ender, 2010, p. 40-43). Student development research tells us that the student's peer group can be the most important influence on his or her development, even to the point that he or she will change his or her values, beliefs, and aspirations "in the direction of the dominant values, beliefs, and aspirations of the peer group" (Astin, 1993, p. 398). More recently, Dennis, Phinney and Chuateco (2005) studied ethnic minority, firstgeneration college students and found that "peer support (or lack of needed peer support) is a stronger predictor of college grades and adjustment than support from the family” (p. 234). Clearly, the influence of one's peers holds particular value for the development of college students and further supports the importance of the peer mentoring role.

The benefits of learning how to create effective mentoring relationships during college can reach beyond the college student experience. Much has been written and said in recent years regarding the roughly 80 million members of the millennial generation, the last of whom are starting to leave college. By the year 2025, this generation will comprise 75 percent of the workforce. Unlike previous generations, these young people realize that they can expect to have upwards of twenty or more different jobs over the course of their lives. A recent study by Deloitte (2016) of young adults across 29 countries found that by 2020, two-thirds expect to leave their current employer. Why is that? Because these young people recognize that if their current employers do not provide the developmental, leadership, and growth opportunities that they are looking for, then for their own career development they necessarily will have to move on to the next position that does. However, 
Deloitte also found that 81 percent of those inclined to leave were more likely to stay five or more years at their current employer if they felt that they were receiving mentoring. Another recent study by Gallup found long-term connections to personal and career well-being if one felt that he or she had a mentor in college who "encouraged me to pursue my goals and dreams" (Ray \& Kafka, 2014). The developmental benefits of effective mentoring extend beyond the college experience, but it is there that these future young professionals start to learn the skills and practices of creating effective interpersonal relationships and networks.

Whether formal or informal, mentoring relationships are traditionally thought of as one-to-one interactions that involve the delivery of guidance, feedback, and lessons learned through direct experience. Historically, these relationships developed out of the apprenticeship model. In this model, an older, senior mentor passed on the wisdom of his experience to his appointed or anointed mentee, who would eventually take his place. Over time, this image of a unidirectional (and paternal) model of mentoring has evolved, and now includes different forms of mentoring. A much more developmental approach is emerging, which places emphasis on the goals of the mentee as opposed to those of the mentor. Also, as individual and organizational needs have changed, greater emphasis has been placed upon the value of personal learning and the need for robust, diverse developmental networks. Mentors ask the mentee to take much greater responsibility for his or her own developmental path and to seek out multiple mentors to fulfill different needs over time (Higgins \& Kram, 2001; de Janasz, Sullivan, Whiting, \& Biech, 2003; de Janasz \& Sullivan, 2004; Lankau \& Scandura, 2007).

Mentoring of college undergraduates occurs at that interesting intersection where a youth population begins to consider adult questions and make adult choices. Therefore, it necessarily must focus on several interrelated outcomes: (a) social and academic socialization to the higher education experience; (b) exploration and development of the potential self; and (c) identification of a future path that aligns with that potential self. Mentoring is particularly well-suited to this work as "consistent support creates a safe climate in which students can take risks and do the work of developing personally and professionally” (Johnson, 2007, p. 49). Furthermore, by participating in effective mentoring relationships with peers and others, students begin to scaffold key skills associated with building developmental networks and continuing lifelong learning, skills that will serve them well in an interconnected world.

Ideally, these relationships would develop within the controlled and structured environment of formal mentoring programs. However, just because formal structures are provided, there are not assurances that mentoring programs will be successful in achieving these goals. Formal mentoring programs single out a particular group for development to the exclusion of others. For the student population on university campuses, these groups tend to fall into one of three categories: those in need of social or academic help; those identified as having high potential for future leadership roles; or those who fall into a particular category such as underrepresented minority or woman or student-athlete.

Furthermore, because most colleges do not have the capacity or the resources to administer a formal mentoring program that will provide a mentor for every single student on campus. Therefore, this sort of segmentation generally results in mentoring programs that target anywhere from 10-100 students and leave a significant population of students to find their informal mentors on their own.

Unfortunately, if undergraduates must identify and secure their own mentors, more often than not this 
doesn't happen or doesn't happen well. If mentoring programs aimed at improving student success are established for only a select few, then the majority is denied that opportunity and support.

At Wake Forest University we are building an interdisciplinary culture of mentoring that aims to achieve the interrelated outcomes of socialization, exploration, and identity-formation as well as building skills of interpersonal relationship-building and personal learning for all students. In June 2010, the university's strategic plan led to the establishment of the Mentoring Resource Center (MRC). The MRC plays a key role in supporting and building connections between students, faculty, staff, alumni, and the community to help align students' passions, strengths, and interests with their goals and visions for what they want to accomplish while at Wake Forest and in their future careers. Rather than manage a formal mentoring program for a select few, the MRC serves as a central office to provide training, support, recognition, and inspiration for all Wake Forest mentoring activities and programs. The mission of the MRC is to make mentoring a visible core experience and value of the Wake Forest community. The vision is to become a nationally recognized leader in higher education mentoring programs and practice. Most importantly, we are shifting our understanding of mentoring from only occurring within a formal program to one of individual skill development and institutional culture change. In the sections that follow, we describe our model, some of our key peer mentoring programs that contribute to our students' successful transition from high school to college to life after college, our metrics for success, and our future vision, and lessons learned.

\section{Background}

Wake Forest University is a private liberal arts institution of 4,800 undergraduates with a total enrollment of 7,669, located in Winston-Salem, North Carolina. At the heart of the campus is the teacher-scholar ideal, which encourages engagement with students both inside and outside of the classroom. This includes, but is not limited to, a long-held tradition of faculty-student advising, beginning with lower-division advisors who guide students through the first two years of college, at which point students transition to their major advisors. Mentorship has long been part of the ethos and guiding principles of the university.

Over the past few years, Wake Forest has taken steps to institutionalize and further support this longstanding tradition and culture of student mentoring. In June 2010, the university established the Mentoring Resource Center, which helps students think more deeply about their lives and make sound decisions. To accomplish this, the MRC provides training, guidance, resources, and support to formal and informal mentoring relationships across the campus community. Wake Forest's mentoring philosophy is based on the importance of developing a network of supportive relationships. These provide guidance, feedback, and wisdom to help college students learn the skills of critical thinking, problem solving, and decision-making on their individual paths from adolescence to adulthood. We define mentoring as building a purposeful and personal relationship in which a more experienced person (mentor) provides guidance, feedback, and wisdom to facilitate the growth and development of a less experienced person (mentee).

The MRC is a centralized office that operates a decentralized model of mentoring. The MRC does not administer any formal mentoring programs, match mentors with mentees, nor do we maintain a master database of available mentors. The reasons for this are two-fold: capacity and continuity. Formal mentoring programs are high-resource initiatives. They do not have to cost a lot of money, but they do 
require consistent oversight and administration. For this reason, successful mentorship programs typically reach no more than 10 to 100 individuals. For us to reach our goal of providing every student with the opportunity to engage in an effective mentoring relationship while they are at Wake Forest, it is essential that we build capacity for those relationships throughout the university. Furthermore, with only one full-time and one part-time staff member, we will never be successful in accomplishing this goal on our own. Therefore, by seeding formal programs in various departments, with identified leaders of those programs, we ensure that those programs will outlast the individual staffing of the MRC into the future.

We also call the MRC approach a "consulting model” in that we consult with individuals across the university to support their efforts in developing mentoring programs and incorporating skills and practices of effective mentorship into their work. We will help anyone develop a mentoring program from inception to evaluation, including identifying potential mentors and mentees, helping with the matching process, providing training, and helping with evaluation. We firmly believe that mentoring programs develop best within the cultures within which they reside. It is also important that programs are created to meet the identified needs of their students; therefore, a professional mentoring program for business students will look quite different from a first-year transition program for first-generation students. As such, much of our work is spent building relationships and collaborative partnerships across campus to determine needs and opportunities to support the work of others. We do not step in and impose our standards onto any mentoring program or group. We do provide content expertise and support for faculty research proposals that have a mentoring component.

As a resource center, a large part of our work is to educate the campus community on what effective mentoring is, and to provide resources to support that work. We conduct trainings for formal programs and for groups of informal mentors like residence life staff and our Faculty Fellows, who are non-residential tenured faculty who have committed to spend time in the first-year residence halls. We create and distribute handbooks, toolkits, and tip sheets through our website; we keep a regular blog and twitter presence, and highlight stories of effective mentoring from members of our community. In 2015, we developed a set of Mentoring Learning Outcomes and associated strategies for both mentors and mentees. Furthermore, we created self-evaluations for participants, in both formal and informal mentoring relationships, to assess their progress towards excelling in each of those competency areas. Moreover, we have launched a quarterly e-newsletter, the Mentoring Minute, as a vehicle to distribute information and resources. In addition, each year in January, we celebrate National Mentoring Month as a point of focus for our entire campus community at the start of the spring semester. These are just some of the ways that we serve as an educational resource to our campus.

The Mentoring Resource Center was born out of the university strategic plan that was developed following the arrival of our current president, Nathan Hatch. That plan identified a need and an opportunity to elevate the role and value of mentoring on our campus. At the same time, the university created the Office of Personal and Career Development (OPCD), where the MRC is housed, replacing the traditional, placement-oriented career services model with one that is holistic and focused on developing students' abilities to be employable for life. By placing the MRC within the OPCD, the university made a strategic decision to connect mentoring with this holistic, studentcentered, skill development model. The MRC staff directly report to the Vice President, who in turn sits on the President's cabinet. This reporting structure communicates the value of mentorship to our 
campus from the highest level. Twice a year, we convene a Program Coordinator Council, comprised of the leaders of formal mentoring programs on campus, for professional development and sharing best practices. Twice a year, we also convene a faculty/staff advisory committee. This committee provides guidance and feedback on the work of the MRC and identifies opportunities for further engagement and outreach on our campus.

\section{Peer mentoring programs}

The Mentoring Resource Center was specifically created to focus on undergraduate student mentoring. Whether faculty, staff, alumni, or other students serve as mentors, the mentee focus stays on the student. This does not mean that other types of mentoring-faculty to faculty, students to youth off campus - aren't happening on our campus; they most certainly are, and occasionally the MRC consults with and provides training for these efforts as well. But we feel that it is important for the center to focus on our mission of developing the interpersonal relationship-building, decisionmaking, and identity-building skills of students making the transition from high school to college to life after college, and creating a campus-wide culture that supports that work.

One subset of the center's work has to do with supporting peer mentoring programs and informal peer-peer relationships that promote student transition and engagement while they are on campus. Individual program goals vary, and the structure of each program is organized to meet those goals. Furthermore, over time, individual programs have made adjustments based on participant feedback about what seems to be working and not working within the programs. What follows is a brief overview of some of these programs, including the MRC's role in their development and administration.

As mentioned previously, Wake Forest has a long tradition of faculty-student advising, a relationship that starts prior to orientation in the fall, and extends throughout the undergraduate years, as the student moves from lower-division to major advisor in the spring of sophomore year. In addition to the assigned lower-division faculty advisor, each incoming first-year student is also assigned an upper-class-person student advisor. Each student advisor is paired with a faculty advisor and approximately ten to twelve first-year students. The faculty advisor guides the first-year students through the college academic process. The student advisor assists with that process and serves as a peer mentor to these new students as they navigate the transition from high school to college. Student advisors are expected to meet with their first-year students throughout orientation week and once a month throughout the first year of college. The roughly 150 student advisors are trained in recognizing first-year transition issues, developing effective peer mentoring roles, building rapport and trust, as well as supporting mentees' academic efforts. A group of 8-10 experienced student advisors is selected each year to serve on the Student Advisor Leadership Council. This group establishes the program's direction, recruits and interviews all applicants, delivers the training, and provides oversight for the successful implementation of the program each year. Each Leadership Council member is responsible for 15-20 student advisors. The Office of Academic Advising manages the program, with the MRC serving in an as-needed, advisory role.

Magnolia Scholars and First in the Forest are two programs that have been created to serve first generation students at Wake Forest. Magnolia Scholars receive scholarship funding to support their academic progress. All Magnolia Scholars and First in the Forest students are provided with 
dedicated support to help them navigate the transition to (and through) college. As part of this support, new students are connected with upper-class-person peer mentors who are also firstgeneration students. These peer mentors meet with the new students, one-on-one and in small groups, throughout the first year. The program is managed by the Office of the Dean of the College; the program director also mentors and advises each of the first generation students throughout their academic career.

First Year in Focus is a peer mentoring program that was created by two staff members in the Office of Campus Life who recognized that, even with all of the support and resources provided during the first year of college, there were some students who were struggling to find their place and to get connected with their peers and with the university. The program started as a men's program only, and a small group of junior and senior men were selected to serve as peer mentors to those first-year males who self-identified as needing and wanting extra support. Over time, the program was expanded to include female-to-female mentoring as well. Each year, the program kicks off in early fall with a formal training session on peer mentoring and first-year transition needs and opportunities. The actual matching with mentees occurs on a rolling basis throughout the year, as first-year students decide that they need the program. For female students, in particular, some of these matches will not happen until early in the spring semester, following the annual sorority recruitment process.

Two of our formal peer mentoring programs are focused on issues outside of first-year transition challenges and opportunities. Omicron Delta Kappa (ODK), the honor society for outstanding seniors, has created a peer mentoring program with sophomores as part of its leadership and service missions. Each year ODK members and their sophomore mentees engage in formal mentoring conversations from mid-fall up to the major selection process in the spring. The sophomores are able to explore their future academic direction with someone who has been there before them. These conversations also allow mentors and mentees to talk about opportunities to engage with study abroad, student organizations, summer internships, and other on and off-campus experiences. The ODK peer mentoring program is one of our programs that is led by a student.

CHARGE is a student leadership development program that operates out of our Office of Campus Life. Each spring eleven teams of seven first-year and sophomore students learn about leadership models, skills, and practices, and develop a project to address a campus need, which they present to senior administrators at the end of the semester. Two upper-class-person mentors work with each team to guide the project research and development process. As well, these peer mentors facilitate the leadership development classes and lead conversations around building collaborative teams, effective communication skills, conflict resolution, and other topics. Four experienced senior mentors provide overarching leadership to the program, including selecting mentors and mentees and designing and delivering the curriculum. The program operates out of the Office of Campus Life.

We of course have many other peer relationships that fall into more of an informal mentoring category, such as our residence life staff, or shorter-term formal relationships, like our pre-orientation programs. Those in the informal category don't necessarily serve as formal mentors to all of the students with whom they engage, but they use the skills and practices of effective mentorship in their everyday conversations and interactions. In our pre-orientation programs, upper-class-person mentors work with incoming first-year students over the course of the three or four days leading up to formal on-campus orientation in the fall, to help ease that transition and talk through challenges and 
opportunities these students may face, as they make the transition from high school to college. Program activities range from social justice projects to faith-based reflection to outward-bound type excursions and are open to all incoming students.

Another shorter-term formal mentoring program we have created is associated with one of our forcredit career courses. These half-semester courses walk students through identifying personal beliefs, values, strengths, and interests, understanding the world of work, creating a strategic job search plan, and making the transition from college to life after college. As part of the third course, strategic job search, students are given the opportunity to work with a young alumni mentor, to talk through issues of change and adaptability, thinking like an employer, and receiving feedback on job search documents. The mentoring relationship occurs over just three meetings and is highly structured. Both mentors and mentees report increased understanding of their roles in the job search process and increases in personal learning. The instructor of record for the course manages the mentoring program and works with the Office of Alumni Engagement to identify and recruit mentors.

Each of the aforementioned programs has been created and is administered by someone outside of the Mentoring Resource Center. The MRC serves each program in an advisory capacity, providing support with training, guidance on administration, and evaluation. Training typically covers: (a) a basic understanding of what effective peer mentors do and how to fulfill those roles; (b) a discussion of issues and needs related to student transition from high school to college; (c) principles of student engagement; and (d) an understanding of how to have a mentoring conversation. In 2015, we realized that we needed to do more than just tell people what skills effective mentors and mentees use; we needed to operationalize those skills into specific strategies and link them to expected best practices. Therefore, we created a set of Mentoring Learning Outcomes to identify these best practice competencies and strategies for all mentoring relationships on our campus, whether student, faculty, staff, or alumni. These Mentoring Learning Outcomes are defined in the section below, and guide our training efforts.

\section{Mentor learning outcomes}

Build and support effective relationships. Actively creates a supportive, intentional relationship with the mentee based on mutual trust, respect, and accountability that creates a safe space for the mentee to work towards personal learning goals. Willingly discloses personal stories and lessons learned through experience. Seeks out opportunities for intentional conversations that support the growth of the mentee. Role models expected behavior for effective relationships.

Provide objective guidance and feedback based on personal experience. Facilitates the mentee's ability to create and work towards specific learning goals by providing objective feedback and guidance on goals and action steps, sharing lessons from personal experience, and serving as a connector to people and resources.

Facilitate reflective thinking. Pushes the mentee to reflect on experiences by asking thoughtful, thought-provoking questions that seek deeper meaning and help the mentee to become more selfaware of strengths and growth opportunities. Seeks out opportunities for intentional conversations that support the growth of the mentee. 
Take ownership for own personal growth and learning. The mentor serves as a role model for mentee growth and learning by employing practices of goal-setting, seeking feedback, and reflection for personal development during the mentoring relationship.

\section{Mentee learning outcomes}

Build effective personal and professional relationships. The mentee takes initiative in building and maintaining relationships with the mentor based on mutual trust, respect, and accountability. The mentee actively creates intentional relationships with more experienced mentors to support work towards personal learning goals.

Set goals for personal growth and learning. Creates goals as framework for the mentoring relationship. Owns progress towards accomplishing goals through process of taking action, asking for feedback, and reflecting on lessons learned for future application.

Ask for and receive feedback. The mentee openly shares progress towards personal goals with her or his mentor and actively solicits feedback on strengths and opportunities for growth. The mentee practices active listening and understands how to receive and respond to feedback in an appropriate manner that maintains relationships.

Reflect on experiences and lessons learned for future application. Intentionally engages in selfreflection after taking action towards identified goals. Mentee openly engages in reflective conversations with mentor regarding lessons learned and future application.

In addition to the Mentoring Learning Outcomes, we created a set of self-evaluation instruments that allow individuals to assess their progress over time in becoming more proficient at these practices. The self-evaluations allow for individuals to compare responses from the start of the relationship, mid-point, and the end of the relationship. Additionally, we can pull and aggregate data across formal mentoring programs and share that data with the program coordinators which helps both them and the center think about how and where we need to improve our training and educational efforts. This serves as another data point for us as we assess mentoring reach and effectiveness on our campus, which is an ongoing challenge.

Each year on average 2300 participate in our formal mentoring programs across our campus, and 785 participate in formal training programs that we facilitate. This number does not fully capture all of the mentoring efforts on campus as many of those occur in that informal space. Each formal mentoring program is responsible for doing its own program evaluation and can choose whether to share those results with the Mentoring Resource Center. Additionally, every other year our Office of Institutional Research conducts the College Senior Survey (see Table 1) and includes several Wake Forest-specific mentoring-related questions; an overview of those results is included below. 
Table 1.

Wake Forest College Senior Survey: Overview of questions related to Mentoring.

\begin{tabular}{|c|c|c|c|c|}
\hline & 2009 & 2011 & 2013 & 2015 \\
\hline $\begin{array}{l}\text { To what extent did you have a person at Wake } \\
\text { Forest you would consider your mentor } \\
\text { (Significant or Very Significant) }\end{array}$ & $36 \%$ & $47 \%$ & $45 \%$ & $56.8 \%$ \\
\hline $\begin{array}{l}\text { How valuable was the mentoring experience for } \\
\text { you at Wake Forest (Significant or Very } \\
\text { Significant) }\end{array}$ & $45 \%$ & $53 \%$ & $46 \%$ & $61.1 \%$ \\
\hline $\begin{array}{l}\text { Please rate your satisfaction with your ability to } \\
\text { find a faculty or staff mentor (Satisfied or Very } \\
\text { Satisfied) }\end{array}$ & $75.3 \%$ & $79.8 \%$ & $79 \%$ & $81.8 \%$ \\
\hline \multicolumn{5}{|l|}{$\begin{array}{l}\text { What would have improved your mentoring } \\
\text { experience at Wake Forest? }\end{array}$} \\
\hline - Training on effective mentoring practices & N/A & $6 \%$ & $10 \%$ & $9.4 \%$ \\
\hline - More information on mentoring programs & N/A & $19.3 \%$ & $24 \%$ & $22.3 \%$ \\
\hline - Information on how to find a mentor & N/A & $26.6 \%$ & $32 \%$ & $30.1 \%$ \\
\hline - More access to my mentor & N/A & $14.2 \%$ & $11 \%$ & $15.5 \%$ \\
\hline
\end{tabular}

As these numbers demonstrate, there is always more work to be done. As we continue to grow programs and build the culture of mentoring on the Wake Forest campus, the Mentoring Resource Center looks for additional ways that we can assess the reach and impact of mentoring efforts. Perhaps more importantly, we continue to be focused on capturing and sharing mentoring stories that describe the sometimes life-changing experience that is a mentoring relationship.

\section{Conclusion}

As we look to the future, we at the Mentoring Resource Center are constantly and consistently focused on ways that we can continue to elevate the mentoring culture on our campus, to develop the critical skills of interpersonal relationship management in our students, and to seek new ways to share resources and tell stories of exceptional mentoring. Since the center's inception, we have focused on starting small, and piloting new efforts, in hopes of building big successes over time. We have also been very clear that any success the center has is dependent upon our ability to collaborate with partners across the university. In the coming year, we are looking to build additional partnerships with our Campus Life and Residence Life staffs as they seek to build new mentoring programs into student organizations and the residence life community. In the fall of 2016, we launched a Mentoring Certificate Program for faculty and staff; in addition we will be piloting an alumni version of the program in the spring. We also are launching a redesigned website in the spring with a stronger focus on storytelling.

One of the keys to our success has been the incorporation of mentoring into the mission, vision, and philosophy of the university. As noted previously, mentoring has always been part of what we do at 
Wake Forest, whether explicitly stated or not. Under the current administration's leadership mentoring has been raised as an aspirational value and key strategy of the university. Having the leaders of the university as champions for our work provides immeasurable support and a voice for us in rooms to which we might not normally have access. Furthermore, our work is completely supported by external funding in the form of donations from students' parents who believe in the value of what we are doing. This monetary support provides the center with a measure of freedom. This allows us to accomplish our goals in an environment that currently sees less money being put towards higher education programs, not more.

Assessment and evaluation is a constant challenge, not only because of the over-surveyed nature of our campuses, but also due to the difficulty in measuring impact of interpersonal relationships. Many, if not most, effective mentoring relationships occur in the informal space, which often cannot be identified or quantified. It happens in a walk across the quad after class, or a shared meal in the campus cafeteria, or in brief exchanges on the intramural field. These "mentoring moments" are no less impactful or meaningful than those that happen within the formal structures of a mentoring program; often those impacts cannot be seen, measured, or identified until years down the road. It is because of this, and because we know that the ability to create effective interpersonal relationships is one that transcends our metaphorical campus walls, that we have become more focused on skill development than on the development of any one program.

We are often asked if other schools or organizations can apply our decentralized, consultant model of mentoring. We firmly believe that they can, given the right support, adequate resources, and the willingness to create the model that works for that organization's culture. Mentoring, whether at the individual, programmatic, or institutional level, is a strategic intervention, and should always be deployed and honored as such. To try to apply a one-size-fits-all model does not do justice to the needs and the goals of the individuals who are participating and who will ultimately be impacted by that intervention. Mentoring, we often say, is an awesome responsibility and one that should not be taken lightly. At the same time, it is an awesome opportunity to create meaningful difference in the lives of students, programs, and institutions. 


\section{References}

Arnett, J.J. (2000). Emerging adulthood: A theory of development from the late teens through the twenties. American Psychologist, 55(5), 469-480. https://doi.org/10.1037/0003-066X.55.5.469

Arnett, J.J. (2004). Emerging adulthood: The winding road from the late teens through the twenties. Oxford University Press.

Astin, A.W. (1993). What matters in college? Four critical years revisited. San Francisco: Jossey-Bass.

Daloz Parks, S. (2000). Big questions, worth dreams: Mentoring young adults in their search for meaning, purpose, and faith. San Francisco, CA: Jossey-Bass.

Deloitte (2016). Deloitte millennial survey 2016. Retrieved from

http://www2.deloitte.com/global/en/pages/about-deloitte/articles/millennialsurvey.html

de Janasz, S.C., \& Sullivan, S.E. (2004). Multiple mentoring in academe: Developing the professorial network. Journal of Vocational Behavior, 64(2), 263-283. doi.org/10.1016/j.jvb.2002.07.001

de Janasz, S.C., Sullivan, S.E., Whiting, V., \& Biech, E. (2003). Mentor networks and career success: Lessons for turbulent times [and executive commentary]. The Academy of Management Executive (1993-2005), 17(4), 78-93. https://doi.org/10.5465/AME.2003.11851850

Dennis, J.M., Phinney, J.S., \& Chuateco, L.I. (2005). The role of motivation, parental support, and peer support in the academic success of ethnic minority first-generation college students. Journal of College Student Development, 46(3), p. 223-236. doi.org/10.1353/csd.2005.0023

Higgins, M.C., \& Kram, K.E. (2001). Reconceptualizing mentoring at work: A developmental network perspective. Academy of Management Review, 26(2), 264-288.

doi.org/10.1353/csd.2005.0023

Johnson, B.W (2007). On being a mentor: A guide for higher education faculty. New York: Lawrence Erlbaum Associates.

Lankau, M.J., \& Scandura, T. A. (2007). Mentoring as a forum for personal learning in organizations. In T. D. Allen \& L. T. Eby (Eds.), The Blackwell handbook of mentoring: A multiple perspectives approach (pp. 95-122). Malden, MA: Blackwell Publishing Ltd.

Newton, F.B., \& Ender, S.C. (2010). Students helping students: A guide for peer educators on college campuses. San Francisco, CA: Jossey-Bass, Inc.

Ray, J., \& Kafka, S. (2014). Life in college matters for life after college. Gallup. Retrieved from http://www.gallup.com/poll/168848/life-college-matters-life-college.aspx

Sanft, M., Jensen, M., \& McMurrary, E. (2008). Peer mentor companion. Belmont, CA: Wadworth, Cengage Learning. 


\section{Author information}

Allison E. McWilliams is the Director of Mentoring and Alumni Personal \& Career Development at Wake Forest University, a role she has held since June 2010. Prior to her current role, she served as a faculty member at the University of Georgia where she led leadership development, organizational development, and mentoring programs. She is a board member of the International Mentoring Association and has written and spoken broadly on the topic of mentoring.

Allison E. McWilliams

Mentoring and Alumni Personal \& Career Development

Wake Forest University

Reynolda Hall, Suite 230

Winston-Salem, NC 27109

E-mail: mcwillae@wfu.edu

Telephone: 336-758-3741

Web: http://mentoring.opcd.wfu.edu/ 